\title{
Learning about the past: exploring the opportunities and challenges of using an outdoor learning approach
}

Article

Accepted Version

Harris, R. and Bilton, H. (2019) Learning about the past:

exploring the opportunities and challenges of using an outdoor learning approach. The Cambridge Journal of Education, 49 (1). pp. 69-91. ISSN 1469-3577 doi:

https://doi.org/10.1080/0305764X.2018.1442416 Available at https://centaur.reading.ac.uk/75257/

It is advisable to refer to the publisher's version if you intend to cite from the work. See Guidance on citing.

To link to this article DOI: http://dx.doi.org/10.1080/0305764X.2018.1442416

Publisher: Taylor \& Francis

All outputs in CentAUR are protected by Intellectual Property Rights law, including copyright law. Copyright and IPR is retained by the creators or other copyright holders. Terms and conditions for use of this material are defined in the End User Agreement.

www.reading.ac.uk/centaur 
Central Archive at the University of Reading

Reading's research outputs online 


\title{
Learning about the past: exploring the opportunities and challenges of using an outdoor learning approach
}

\author{
Richard Harris and Helen Bilton \\ Institute of Education, University of Reading, UK \\ r.j.harris@ @reading.ac.uk \\ ORCID ID orcid.org/0000-0001-8606-5515, Twitter@RH47R
}

Tel 01183782725

Richard Harris is an associate professor in history education. His interests are mainly related to the history education, especially issues relating to the curriculum, how it is perceived and conceptualised, as well as the place of diversity within the history curriculum and the public and political discourse around history education.

Helen Bilton is Professor in Outdoor Learning. Her research concerns the early years teaching and learning environment: how to organise and manage it to ensure all areas of the curriculum are covered and children develop holistically. Her recent research has been about ensuring outdoor environments are language rich. 


\section{Learning about the past: exploring the opportunities and challenges of using an outdoor learning approach}

This paper examines the potential of outdoor learning for supporting children's understanding of and attitude towards history. A class of primary school children participated in an intensive experiential, residential history programme. A range of data were collected before, during and after the residential programme, and the findings suggest that the experience had a positive impact on the children's attitude towards history, and enabled many of the children to be able to recall easily highly specific factual knowledge. However the children's understanding of history as a provisional construct was not developed, as it was not a strong feature of the programme. Nor was the experiential nature of the experience fully exploited. Overall the study suggests that such a programme has the potential to support children's learning of the past, but a deeper understanding of history, drawing on the benefits of outdoor learning pedagogy needs to be planned for more explicitly.

Keywords: history education; outdoor learning; experiential learning; primary education

\section{Introduction}

There are strong educational reasons, particularly relating to personal and social development, for young children to learn in an outdoor environment. These are widely recognised both by educationalists (e.g. Dillon, Morris, O’Donnell, Reid, Rickinson \& Scott, 2005; Rickinson, Dillon, Teamey, Morris, Choi, Sanders \& Benefield, 2004) and policy makers (DfES, 2006; House of Commons 2010). Yet in some contexts teachers have found it hard to engage with outdoor learning (e.g. Maynard \& Waters, 2007). One reason for this is the growing emphasis on measurable academic outcomes; this is an international phenomenon, part of what Connell (2013) calls a 'neoliberal cascade', with the development of educational policies, whereby teachers are held accountable for 
academic outcomes in national and international high stakes tests. This is in spite of growing criticism about how these measures distort educational policies across Europe, northern America and Australasia (Ball, 2017; Goodson, 2010; Levin, 2010). The focus on academic achievement has also seen policy makers look closely at the curriculum with a view to using this as a mechanism to raise standards (e.g. Winter, 2012). This has caused a dilemma for many teachers; whilst recognising the value of outdoor learning for 'soft' skills and broader personal development (e.g. Dillon et al., 2005; Rickinson et al. 2004), there is less compelling evidence about the academic benefits of outdoor learning. Without this evidence teachers will find it hard to adopt outdoor education as a legitimised pedagogical approach to learning.

This paper has two foci. First, to examine the academic benefits of outdoor education for history, as it is a subject not usually researched regarding outdoor learning. Second, to explore the impact of outdoor learning on children's attitude towards history. This latter focus stems from a relative absence in the research literature about the impact of an outdoor approach on attitudes towards specific areas of the curriculum; much of the research focuses on attitudes towards learning in general, towards the self, or towards environmental issues (Rickinson et al. 2004).

The study was conducted at an outdoor learning centre in the south of England, which has a broad ranging history programme, delivered through a series of day and residential activities. The research reported here forms part of an evaluation requested by the centre. This offered a rare opportunity to examine the effectiveness of an outdoor learning approach for history education

\section{Literature review}


The literature for this study draws on three different areas. First, the benefits of outdoor learning for students; second, the pedagogy of outdoor teaching and learning; and finally literature relating to history education.

The benefits of outdoors education can be categorised into the cognitive (knowledge, understanding, academic outcomes); affective (attitudes, feelings, beliefs, self- perception); social/interpersonal (about others, involving communication skills, self-perception and leadership); and physical/behavioural (fitness, skills, actions and personal behaviour) (Rickinson et al., 2004). The evidence for the benefits to social/interpersonal and affective domains is more extensive whereas the cognitive and physical/behavioural benefits are less well explored (Dillon et al., 2005; Rickinson et al., 2004).

Where there is evidence of an impact on academic performance, such as Hattie, Marsh, Neill and Richards' (1997, p. 68) meta-analysis, the results are 'most impressive'. However one of the issues with many studies which make such claims is the lack of clarity regarding what is meant by cognitive gains. For example the findings from SEER (2005) conclude that outdoor education is associated with improved outcomes on standardised tests in reading, maths, language and spelling. Yet it is difficult to make any direct connection between children studying outdoors and their improvement in, for example, reading comprehension, as it is not clear whether the higher test scores were due to the use of a set of specific instructional strategies schools employed on the programme (e.g. cooperative learning approaches), or the use of outdoor learning per se. Similarly, although Quibell, Charlton and Law (2017) found a strong association between outdoor education and gains in English, maths and science tests, they were unable to determine whether this was a result of being in an outdoor environment or whether other factors, such as group size, were significant. In another 
example, Kendall and Rodger (2015) show a clear connection between 'learning away' and stronger examination outcomes (in Maths, English and Science) for secondary aged students. However it is again not clear whether students had a deeper understanding of the subjects studied because of how and what they were taught or whether improvements were to do with the impact on students' self-esteem or improved relationships between staff and students, i.e. were changes attitudinal as opposed to cognitive. As Humberstone and Stan (2011) highlight, teachers adopting less controlling approaches in an outdoor setting fosters children's sense of independence, decisionmaking and self-esteem. Taken together these studies imply relationships do more to promote improved academic outcomes rather than outdoor learning in itself.

In addition there are relatively few studies that are clear about the precise cognitive gains expected from such outdoor education. Nundy's (2001) study on primary school children's understanding of the physical geography of a river is more focused, as it report on students' ability to recall knowledge and their ability to explain their results as well as develop their investigative skills. Although the study notes differences between the outcomes of a control group and an intervention group, it is unclear what the expected learning outcomes were, and therefore what precise impact the work had on students' understanding.

Overall the literature suggests that promoting stronger academic outcomes through outdoor learning needs to have: clear aims; coherence between these aims and the curriculum; pedagogical practices which carefully facilitate learning; experiences which are repeated and intensive; carefully designed preparatory and follow up work to ensure the outdoor aspects of learning are integrated into a broader learning experience (Rickinson et al., 2004). Of these points, many of the studies cited are stronger on pedagogical practices (and which seem to impact on relationships between staff and 
pupils and pupil's levels of self-esteem, as much as understanding of a subject) and seem less clear on defining subject specific aims.

Another area to consider is the pedagogy associated with learning outside. Outdoor education includes, for example, fieldwork, visits, adventure education, and use of school grounds/community projects, and, as Williams and Wainwright (2016b, 592) argue, experiential learning is a 'non-negotiable' feature of any form of outdoor learning A particular affordance of experiential learning is the opportunity to make abstract ideas concrete and more readily accessible. Two key theorists in experiential learning, namely Dewey (1971) and Kolb (1984), have influenced approaches to outdoor education (e.g. Howden, 2012; Taniguchi, Freeman \& LeGrand Richards, 2005; Williams \& Wainwright, 2016a). Their work offers a potential pedagogical framework. Dewey's (1971) ideas outline a careful process of 'trial and error', whilst Kolb's (1984) model identifies a cycle of concrete experience, reflecting on the experience, drawing out principles or generalisations through a process of abstract conceptualisation, and then applying these in different contexts in a process of experimentation. Essentially outdoor pedagogy offers children opportunities to draw upon their ability to think, physically test ideas and to experience success and failure.

The literature is replete with examples of studies focused on environmental, geographical and scientific topics being taught outdoors, but examples relating to history education are sparse. Understanding the nature of history teaching is however essential if an outdoor approach is going to be successfully adopted. Some debates about history education identify a crude dichotomy between history as a body of knowledge versus 'skills' (e.g. Phillips, 2002). On the one hand are those that regard the purpose of history as mastering a body of knowledge (often in the form of dates and events), as illustrated by Hirsch's (1987) model of cultural capital. In contrast, the 
Schools History Project of the 1970s, developed in England, promoted the need for students to 'do' history and therefore learn, for example, how historians work with evidence to construct the past. Ultimately this distinction is unhelpful, as learning history requires students to learn substantive content knowledge, and understand how history operates as a discipline (Lee, 2011), i.e. history is both a body and form of knowledge. Students need detailed knowledge to work with, but this is combined with understanding history as a process of enquiry, working with evidence, which may result in differing interpretations of the past, learning how to use second order concepts, such as causation, and change and continuity, to shape and organise how we analyse and explain the past, and developing an understanding of substantive concepts, such as power, democracy and so forth (e.g. Kitson, Husbands \& Steward, 2011).

There have been debates recently about substantive knowledge in history, essentially considering how students use such knowledge. The debates can be divided into two distinct areas of professional discourse. One looks at how children are helped to construct a 'usable' framework of knowledge, to build a mental 'map' of the past that is provisional, within which new knowledge can be incorporated. This allows new connections and comparisons across time to be made (e.g. Howson \& Shemilt, 2011). The other, which is very much part of current professional discourse, looks at 'making history stick' (e.g. Fordham, 2014). Here the focus is on helping students retain knowledge securely so it can be confidently applied to answer a range of questions. This is of particular concern to secondary school teachers looking to enhance their students' understanding of history and ability to tackle examinations successfully (e.g. Hammond, 2014).

In many ways history is a difficult subject for children to learn, because it is highly abstract, requiring considerable conceptual understanding (Husbands, 1996). The 
substantive content of the subject is often beyond children's lived experiences, which makes it abstract. The notion of time itself is very conceptual. Being able to understand that people in the past had different mindsets, and being able to appreciate these and to empathise with different views is a challenge (Ashby \& Lee, 1987). Many children struggle to understand that our knowledge of the past is incomplete (Shemilt, 1987). Outdoor, experiential learning offers a possible means of making an abstract subject like history concrete and therefore more intelligible to young people. Yet the literature does not really explore how outdoor learning could assist with understanding history. It would therefore appear to be an area worth investigating further. It would also be worth seeing whether outdoor learning specifically supports the development of children's substantive historical knowledge, as well as their ability to explore how we know about the past and how the past is therefore constructed and presented.

In summary then we have attempted to identify the potential advantages of learning outside, utilising a particular experiential approach, setting this alongside a curriculum subject which might benefit from being taught outside. Figure 1 illustrates a potential relationship between these elements: at the heart should be the different aspects of history that are the intended outcomes (i.e. development of knowledge, concepts and processes), the experiential learning cycle which provides the pedagogical approach, leading to the range of potential outcomes. Any learning in relation to history should develop the dimensions relating to content, concepts and the process of enquiry shown. This does not mean that all three dimensions should be developed simultaneously but any focus on substantive knowledge should ideally be linked to developing children's conceptual and/or procedural ways of thinking at the same time. The experiential learning cycle (Kolb, 1984) can provide the means to teach the subject. For example pupils could explore how we find out about Anglo-Saxon culture using 
artefacts, they can then work with artefacts and infer from these what we can learn about Anglo-Saxon society. They can then reflect more generally on how we find out about the past, identify key generic issues relating to interpretation of evidence and the limitations of some forms of evidence, and apply this insight into other topics or work with other forms of evidence.

[Insert Figure 1 here]

Figure 1 - exploring the relationship between the benefits of outdoor learning, Kolb's (1984) experiential cycle of learning, and the dimensions of history education

We sought to explore the extent to which the outdoor learning approach outlined above led to particular learning gains in relation to substantive, conceptual or procedural knowledge within history. We also wished to find out whether the use of an outdoor approach altered children's attitude towards the subject. This investigation therefore adds to the literature on outdoor learning where history has received scarce previous research attention, as well as exploring the impact on attitudes, which was an issue the outdoor centre was keen to examine.

Thus two research questions were posed:

- How effective was the use of outdoor learning activities for supporting children's learning of history across the domains of content, concepts and process of enquiry?

- To what extent did the use of outdoor learning alter children's attitude towards history as a subject?

\section{Research design}

This exploratory study focuses on the experience of one primary school which participated in a two day, residential programme at an outdoor learning centre that 
specialises in history education. The school had not participated in activities at the centre beforehand, and was selected for involvement in the project purely on grounds of convenience.

The programme focused on a sequence of activities related to the Vikings for a class of 30 children, made up of 14 girls and 16 boys (combining learners from Years 3 and 4,aged 7-9). The school was in a rural setting, with many children coming from homes of higher than average socio-economic status. There was a nearby military base from which several children came. Their teacher had been employed at the school for nearly four years, and this was his first post since qualifying.

The visit took place during the autumn. Figure 2presents its key features and how they might be categorised using Kolb's (1984) experiential cycle of learning:

[insert Figure 2 here]

Figure 2 Activities experienced during the residential programme

To ensure that there was sufficient depth and breadth within the data gathered to provide an overall picture of the children's experiences we adapted the mosaic approach (Clark \& Moss, 2001), gathering data from the class teacher, parents, and children. The specific tools used with the children (Appendices B, C and E) had been developed by Foley (2016) for a study exploring pupils' attitude towards mathematics. As we were also looking in part at children's attitude towards a curriculum subject these tools were considered appropriate, especially as they had been used with the same age group. The data were gathered in three stages. The first was prior to the residential experience and was designed to provide a baseline from which the children's attitude towards and knowledge of history could be compared. The second collected data during the residential and the final stage was six weeks after the residential experience and was 
designed to gauge any longer term impact on the children's knowledge of and attitude towards history. Overall the approach was largely exploratory, qualitative and interpretive, although some of the data collected was quantitative.

\section{Research methods}

Four forms of data were collected. Interviews were conducted with the class teacher and pairs of children, parents were surveyed, the children were asked to fill in worksheets, and field observations were made during the residential programme.

In the first stage there was an interview with the class teacher to identify what he hoped to gain from the visit, his experience of learning history, and how he taught the subject. This would help gauge whether the children were familiar with history as a body and/or as a form of knowledge. A parental survey (see Appendix A) was used to assess their child's level of interest in and attitude towards history, using a five-point Likert scale to respond to statements, as well as an open-ended question. Finally, data were gathered from the children. The children were given about 40 minutes in class to work on a metaphor sheet (if history were a ... it would be ...) (see Appendix B) and to draw themselves learning history. These were designed to see what the children felt about history. The tasks were administered by the class teacher, one of the researchers and a classroom teaching assistant. The tasks were explained to the class by the researcher and the children were then able to work on them with support from the adults in the room. The teacher was asked to choose children who would be comfortable talking to one of the researchers, and chose six pairs of Y4 children (i.e. 12 out of 14 Y4 children). Each interview lasted around 10-15 minutes. The interviews were also designed to explore whether the children liked history (and so could provide a point of triangulation with data from the metaphor sheets), and why they had a positive or 
negative attitude towards history. The interviews also explored the children's knowledge of the Vikings and what they understood history to be.

Stage two was carried out during the residential programme. Two researchers were on site during the two days to observe the activities and how the children engaged with these. One researcher was on site the whole time and the other was there for the majority of day one and the start of day two. The researchers kept field notes from the observations. One focused mainly on the activities and the type of history that was being stressed (e.g. substantive content). The other researcher focused primarily on the children's level of engagement using Laevers' (1994) engagement scale, looking at both the entire group and four children, who were immediately visible on arrival by their behaviour- overly reserved or overly demonstrative. This scale was adopted to see whether the children were positively engaged with the activities and had high levels of well-being. Nine signals are looked for, namely concentration, energy, complexity and creativity, facial expression and posture, persistence, precisions, reaction time, language and satisfaction. The researcher observes the children for two minutes and makes a judgement about the overall level of engagement; not all signals are likely to be evident for each period of observation, so any judgement draws on what was observable at a given point in time. Levels of involvement and well-being are measured on a five point scale, with 5 indicating children are fully engaged and working at full capabilities and 1 indicating children are not engaged at all and showing signs of withdrawal.

Interviews were repeated on day two, at breakfast time, with the same six pairs of children, in particular exploring what they had learnt and whether they had found the experiences so far enjoyable. At the end of the residential programme all the children were asked to complete a 'gingerbread person' worksheet (see Appendix C) to identify what they had enjoyed, what they had learnt and what things could be done differently 
or added to the residential experience. The class teacher was also interviewed about his views on the residential programme the class.

The final stage was conducted six weeks later to ascertain what longer-term effect the residential programme had had on the children specifically regarding their attitude towards history and what they had learnt. Parents were surveyed again (Appendix D) to see if they had noted any difference in their child's attitude and interest towards history. The class also completed a word wheel (Appendix E) to identify what knowledge they learnt from the programme. This time the class teacher asked to administer the task without the presence of the researcher. It had been intended that the children would draw themselves doing history again, in order to see if there were any changes in what they drew, but unfortunately the teacher was unable to find the time for the class to do this activity. The children who had been interviewed previously were interviewed for a final time to examine what they had learnt about history and whether they had found the subject more interesting as a consequence of their experiences.

\section{Data analysis}

All the interviews were inductively coded by one of the researchers, using an open coding process to identify initial issues and themes. The interviews with the children focused mainly on their attitude towards and enjoyment of the subject, and their understanding of history. The children's comments about attitude and enjoyment were finally categorised along a continuum from positive to negative comments. The children's understanding of the subject was divided into comments about substantive knowledge and those about history as a form of knowledge. For example any comments that simply mentioned facts the children had learnt were taken as evidence of the children seeing history as a body of knowledge, whereas any comments about how we 
have come to know about the past would be a signal that the children were starting to understand that history is a form of knowledge.

The parental surveys provided largely numerical data and a simple snapshot of perceived changes in children's attitudes towards history as seen by their parents. Fourteen were returned, so given this small number of response it was deemed inappropriate to conduct any statistical tests, and so figures are presented as raw numbers.

The worksheets completed by the children were approached in different ways. The responses on the metaphor sheets used in the first stage of data collection were coded by one of the researchers and divided into positive, ambivalent and negative feelings about history. The drawing task was subject to content analysis; essentially the images were coded as to where history was being studied, what tasks were being done and who was in the picture. The frequency of particular ideas was then counted. The children were asked to use the word wheel to record what they remembered learning; the data was tabulated and the frequency with which particular topics were mentioned by individual children were counted. The interviews also meant that it was possible to triangulate the findings from the worksheets with comments made in the interviews.

Ethical approval for the project was granted by the university in which the researchers were based, following its procedures and those of the British Educational Research Association (BERA) (2011). Information sheets were provided for all those involved and consent was requested from all those involved.

\section{Findings}

RQ1: How effective was the use of outdoor learning activities for supporting children's learning of history across the domains of content, concepts and process of enquiry? 


\section{Pre-visit findings}

The interview with the teacher revealed he had little interest in history at school, and teaching it had formed a tiny aspect of his teacher training. Consequently his experiences were limited and he saw history as a repository of interesting factual information. He was unconcerned about what the children might learn on the residential as long as they had an enjoyable time, which would make learning memorable. The children also saw history as being the acquisition of knowledge. This was suggested by the drawing task. Of the 22 completed pictures, 21 showed the children working indoors, and of these, 16 showed the children working at either a desk, reading books or using a computer, suggesting a view that history is an 'information' subject; two other pictures showed the children completing worksheets, which suggests an emphasis onthe factual nature of the subject. In the interviews, when asked to describe what they had done in class most said they had done a drawing of a Viking longship, and that they had completed a factsheet on Alfred the Great and Athelstan. Generally the tasks described were about gaining factual knowledge. This suggested that the children regarded history as a body of knowledge to be mastered. None of the children gave any indication that they understood history to have been constructed from relics of the past.

\section{Visit findings}

Field notes show that the focus of the activities was strongly centred on acquiring substantive knowledge. For example the Viking 'voyage' was mainly about where the Vikings travelled and what they obtained from different places, the spinning, grinding and torc making were about what the Vikings did, and the Viking battle was about the sequence of events, although in this case there was an attempt to try to explain why the Saxons were able to defend their territory from the Vikings. The preparation for the 
Viking feast, which was held in the evening, did make some reference to how we know about the Vikings, mentioning the value of sagas, but this was not strongly emphasised. Interviews with the children focused on what they had enjoyed and learnt so far. They were all able to identify specific pieces of information they had acquired. Interestingly the children had very different perceptions of the Vikings as a result of the activities on the first day. One pair of girls felt that the Vikings were not very clever because of the clothes they had and their limited technology. This reflects a classic perception many children have of past societies, which are regarded as inferior based on comparisons to modern society. Conversely another pair of girls showed more sophisticated insight as they recognised the Vikings as clever and skilful because they were able to make the things they needed; the activity relating to spinning had apparently made some of the children think differently. Yet another group were surprised about how many countries the Vikings had been to, and that they travelled by using the stars. Enabling children to appreciate the skills and sophistication of people in the past is a really valuable element of learning about the past, as it demonstrates the ability to contextualise past societies and to empathise with the lives of others. Interestingly these findings show how the children were making sense of new information for themselves and how they were using this to make judgements about the Vikings, devoid of adult input. It was noticeable from the way the activities were conducted that little attempt was made to identify the children's prior knowledge and conceptions of the Vikings, and there were few attempts during the residential programme to help the children make connections between their existing knowledge and any new knowledge.

A 'gingerbread' person sheet was completed at the end of the residential to capture what the children felt they had learned. The emphasis was on factual knowledge; some children mentioned specific details, such as how many people would 
be in a Viking longboat, whereas others were more generic, for example the Saxons eventually beat the Vikings. However, all the children did write something in response to this showing they had all gained some new factual knowledge.

The teacher was also interviewed at the end of the two days. He felt the children had enjoyed the programme, which he thought would help them internalise more readily knowledge of the topic. This again illustrates his understanding of history as an accumulation of factual knowledge. In addition he was impressed by the amount of material that had been covered and the pedagogical approaches used.

\section{Post-visit findings}

To ascertain what the children had learnt about the Vikings the children completed a word wheel, and the same pairs of children were interviewed one more time. The word wheels (see Table 1) showed that the children were able to recall quite specific details (although some were vaguer) six weeks after the residential visit.

[Insert Table 1 here]

Table 1 - frequency with which children identified what they had learnt

This was also evident in the interviews - in two cases the children needed some prompting, but then recalled a lot of detail. In particular many were able to name places the Vikings had travelled to and what they got from the different places, they were able to describe how wool was spun, what Vikings ate, games they played and some details about the sequence of battles that had been re-enacted. Given these activities had taken place several weeks earlier the use of outdoor pedagogy had made some of the knowledge 'stick'. The teacher, when interviewed, was also delighted with what the children had been able to retain and felt that the residential activities allowed him to cover more history in two days than he could over an entire term. 
However the children still perceived history as a body of knowledge to be acquired. Only one child mentioned anything about history being a body of knowledge that is constructed. This was in relation to one of the activities they had done in school following the visit, where groups had given presentations about longships. She explained she had learnt that our knowledge of what we think longships look like is derived from the remains that have been discovered, consequently she appreciated that there may be things about the past of which we are unware simply because relics have not survived. This suggests that some of the children are able to develop more sophisticated levels of historical thinking but this was not something she had been explicitly taught.

RQ2: To what extent did the use of outdoor learning alter children's attitude towards history as a subject?

\section{Pre-visit findings}

The teacher felt that the children generally enjoyed history, citing the popularity of 'Horrible Histories' and children's typical curiosity in finding out facts. This was supported by the majority of parents who returned their surveys. Fourteen (out of 31) were returned to the school. Most felt their child had a positive view of history and enjoyed learning about the past, both in and out of school. As can be seen in Table 2 only one parent felt their child did not show any interest in history per se.

[Insert Table 2 here]

Table 2 - summary of responses from parental survey

However the children showed a more mixed response. Out of 28 children present on the day, 24 handed in their metaphor sheets. Ten indicated they liked history, three were indifferent and six disliked it (five of the metaphor sheets were not included 
as the children had misinterpreted the task). In most cases where the response was positive the children simply included things they liked as part of the metaphor, e.g. citing their favourite food, to show they liked history. Amy ${ }^{1}$ likened history to pepperoni pizza, explaining that she liked pizza but didn't know much about pepperoni pizzas and so was intrigued to find out, which was how she felt about history. Brenda was more indifferent towards history; she likened history to ice cream which she liked, but also said it was like mist which was 'confusing and difficult', and she also likened it to a giraffe, because 'history is a big thing and so is a giraffe', implying perhaps that there is a lot of history to learn. Chris did not enjoy history, saying it was like spaghetti, which was 'tricky' to eat, was like a fog and therefore 'confusing', and said that if it were a colour history would be grey.

Of the twelve children interviewed, six expressed positive views about history, three were ambivalent, and three did not like doing history in school; these responses correlated to their metaphor sheets. Even for those who liked history this was not always linked to learning history in school. Four pupils said they did not like it because they felt they had to remember lots of facts. Two pupils did not like the amount of writing and copying they did in class. Three of the girls also said they were more interested in the things they did themselves outside of school; one was really interested in the Victorians (which had not been taught in school), two others liked to play games where they were characters in the past and would act out different scenarios. One girl did not like history in school because she preferred more creative, craft type activities.

\footnotetext{
${ }^{1}$ All names have been changed
} 


\section{Visit findings}

Field notes showed generally positive levels of engagement from the children. Data collected using the Laevers' engagement scale highlighted a number of positive elements. The four focus children all with quite different personalities and approaches were positively engaged at some level when observed. Even one child who was clearly quite anxious about the experience was listening and took care in their responses. Overall, when watching the children as a group many of the activities had a high engagement level; persistence and energy was demonstrated but there was a general lack of intellectual challenge. Interviews with the children and the 'gingerbread' activity also showed that overall the children had found the activities thoroughly enjoyable.

\section{Post-visit findings}

The follow up data did reveal a positive shift in the attitude of many children towards history. Sixteen parents responded to this survey. Of these eight had responded to the initial survey making some comparisons possible. Overall the responses (Table 3) show heightened interest in history in a variety of ways. Over half the children were seen as being more interested in history at school, with many also wanting to do more history related activities outside of school.

[Insert Table 3 here]

Table 3 - summary of responses from parental survey following the residential stay

Of the eight parents who only responded to this second survey three indicated their child had shown a more positive attitude and interest in history; for the five that generally disagreed it was unclear why this was, especially as many wrote positive comments about the experience, for example: 
David thoroughly enjoyed his Viking experience and we've enjoyed sharing what we know about the Vikings!

Brenda really enjoyed the trip and spoke very enthusiastically about it afterwards but I don't think it's encouraged her more to learn about history. She does enjoy watching horrible histories though!

Edward really enjoyed the trip and liked telling me all about it for quite a few days afterwards.

Freya was very enthusiastic about all the activities that she took part in. She particularly liked all the craft activities.

The eight responses from parents who had also completed the first survey provide a useful point of comparison. In two cases, there was little change in the children's engagement with history but this was because the children were already very interested in history beforehand. In the other cases there was some positive improvement detected by parents; five responses indicated higher levels of interest in response to at least five of the statements, whilst in the other case there was a more positive response relating to two of the statements. Although it is difficult to claim that the visit made all the children more interested in history, it is clear that the parents felt it had had a positive impact on their children.

This was reinforced by the children interviewed. Ten of the twelve children said they now found history more enjoyable:

We really enjoyed it - it was a really fun place to be and helped us loads (Jane and Amy)

It was one of my most favourite things I have ever done (Ken)

I learnt more whilst staying there than at school. It is the best experience I have ever had (Luke)

Two, who had previously disliked history due to the amount of information they were expected to retain, had found it easier to remember things. The children's level of interest was shown in different ways; four had taken books out of their local library on 
history topics, two others had watched more TV programmes about history, but most said they enjoyed history in the classroom more.

\section{Discussion}

The overall experience was very positive and was clearly memorable and enjoyable. The feedback from the parents and children show a more positive attitude towards history. The level of detail that the children were able to recall several weeks after the residential programme was impressive and suggests that the programme had had a demonstrable impact on the children's learning. It appears that the intensive nature of the visit, supported by the staff at the centre with expertise in history education, the use of hands on pedagogical approaches, as well as the strong experiences this provided, helped the children to learn and retain a wealth of detail, and also had a positive impact on their attitude towards history. As such these findings support previous studies such as Nundy (2001) and Kendall and Rodger (2015).

However the academic gains are quite limited and there appear to be missed opportunities to maximise the potential of the outdoor experience. Several of the points identified by Rickinson et al. (2004) for successful outdoor learning were not strongly evident. There were few explicit links made between the residential programme and the school's history curriculum, largely due to the teacher's limited goals for the children, and thus there was little in the way of preparatory and follow up work. Also the focus of the staff at the centre was teaching the children about aspects of Viking life rather than the process by which we come to know and understand about the past; hence there was not an explicit focus on the disciplinary nature of history.

Looking at Figure 1, there were also missed opportunities for learning through limited application of an experiential pedagogy. The children certainly experienced a range of practical, hands on activities and also had the opportunity to act out many 
events. This sits firmly within the realm of concrete experience (Kolb, 1984). Yet there were few guided opportunities to move beyond this into the abstract level, which could have helped develop the children's conceptual understanding of history. As noted in the findings, several children did reflect on their experiences (so were following Kolb's cycle of learning) and were forming their own impression of the Vikings, with varying degrees of sophistication. However there were few supported opportunities to help the children to think more abstractly and develop a more nuanced view of the Vikings Although reflection can occur naturally, it often needs prompting and questioning to open up alternative ways of thinking, before looking to draw general principles or ideas. For example a number of the activities would have helped create a negative, stereotypical view of the Vikings as violent raiders and looters, especially as the children were encouraged to shout out murderous slogans and battle cries in several activities. Whereas with some guided discussion and reflection the children could have appreciated the skill and resourcefulness of these people, and so develop a more nuanced perspective.

Although there were some academic gains these were firmly focused on substantive content knowledge. The sessions were often skilfully led but their aims seemed to have focused almost entirely on providing the children with substantive knowledge of the Vikings and their way of life. As Lee (2011) argues historical literacy requires both substantive knowledge and knowledge of history as a discipline. A second order conceptual focus, such as why were the Saxons ultimately able to defend their land, or a procedural focus, like how do we know what a Viking house looks like (especially as there were several replica buildings in the grounds), would provide a higher degree of cognitive challenge and develop the dimensions of historical literacy (Lee, 2011). Only one child, in a post-visit interview, gave any indication that our 
knowledge of the past is dependent on and limited by the remains that have survived, but this was not the deliberate focus of any teaching. However the level of detail the children were able to recall after several weeks suggests that the outdoor experience helps with the 'stickability' of knowledge (Fordham, 2014). This offers an interesting focus for future exploration. At present this is an issue mainly being explored in the professional practice of secondary history teachers (e.g. Fordham, 2014; Hammond, 2014) and there is little academic research in this area. As the children's recall of factual detail was impressive, it would suggest that outdoor learning provides an intensive and memorable learning experience. It would seem appropriate to conclude that if children's substantive knowledge can be developed through this approach, then it should also be possible to develop children's understanding of history as a discipline, and therefore develop their overall historical literacy.

Another issue revolves around coherence and the potential of developing a framework of knowledge (Howson \& Shemilt, 2011). The process of reflection and abstract conceptualisation, even if focused purely on substantive content knowledge, should allow young people to develop a coherent, provisional framework of knowledge, which they can then use to compare and contrast to other societies in the past. The way in which the activities were sequenced did not provide a clear narrative to the children, nor were they encouraged to see the activities as building towards a 'bigger picture' of the Vikings. As such the knowledge the children gained was disconnected and discrete. Through more explicit explanation and reflection, the children could be helped to see how the different features of Viking life provide a more rounded perspective on people in the past. This could also help address any issues over unconsciously presenting particular stereotypes (Ashby \& Lee, 1987). 
In terms of the development of positive attitudes towards history, this outdoor learning experience seems to have had a positive impact on the children. Most of the comments from the children in their final interview suggest that the residential activities were fun. This seems to be in contrast to their earlier conception of history as an isolated activity, focused largely on reading as shown in their pre-visit drawings. The reasons for this can only be speculated at, but the difference between a 'book-based', fact finding classroom pedagogy and an outdoors, experiential approach is stark. Also the ease with which the children were able to recall details seems to have made the subject seem more 'doable'. It also seems from what the children said that their teacher had included a number of activities, such as practical craft activities and presentations, which they had not previously done in their history lessons.

\section{Conclusion}

The opportunity to examine outdoor learning specifically devoted to learning about the past is unusual, and the findings are generally positive. The intensity of the experience, the value of hands on pedagogy, led by enthusiastic and motivated staff were important factors in providing a memorable learning experience. This impacted on the children's attitude towards history, and allowed them to gain a considerable amount of knowledge, which they were able to recall quite accurately several weeks later. This approach clearly has potential to make history seem a valuable and interesting subject. Any limitations in terms of the children's historical literacy and abstract thinking rest with a narrow conceptualisation of both history and outdoor learning. There was an almost exclusive focus on history as a body of knowledge. Given the impact the programme had on the children's knowledge and its 'stickability', it does suggest that broadening the conceptualisation of history within the programme could potentially have a profound impact on the children's understanding of the nature of history. This requires 
the staff involved in the planning and leading of the programme to have a wider concept of history for this to be realised. Although this should also be combined with a stronger implementation of an experiential pedagogy that goes beyond the concrete, and allows for reflection and abstraction. If approached correctly, outdoor learning has the potential to provide strong learning gains in all areas of the curriculum.

\section{References}

Ashby, R. \& Lee, P. (1987) Children's concepts of empathy and understanding in history. In C. Portal (Ed.), The history curriculum for teachers (pp.62-88). London: The Falmer Press.

Ball, S. (2017). The Education Debate ( $3^{\text {rd }}$ ed.). Bristol: Policy Press.

Clark, A. \& Moss, P. (2001). Listening to young children: The mosaic approach. London: National Children's Bureau.

Connell, R. (2013). The neoliberal cascade and education: an essay on the market agenda and its consequences. Critical Studies in Education, 54, 99-112. doi: $10.1080 / 17508487.2013 .776990$

Department for Education and Skills (DfES) (2006) Learning outside the classroom: manifesto. HMSO DfES. Retrieved from http://www.outdoorlearning.org/external affairs policy/lotc_manifesto.pdf

Dewey, J. (1971). Experience and education. New York: Collier Books, (Originally published 1938.)

Dillon, J., Morris, M., O’Donnell, L., Reid, A., Rickinson, M. \& Scott, W. (2005). Engaging and learning with the outdoors: The final report of the outdoor classroom in a rural context action research project. Slough: National Foundation for Educational Research.

Foley, C. (2016). Girls' perceptions of mathematics: an interpretive study of girls' mathematical identities (unpublished doctoral thesis). University of Reading, UK.

Fordham, M. (2014). Making history stick part 1: principles. Retrieved from https://clioetcetera.com/2014/08/06/make-history-stick-part-1-principles/ 
Goodson, I. (2010). Times of educational change: towards an understanding of patterns of historical and cultural refraction. Journal of Education Policy, 25, 767-775. doi: 10.1080/02680939.2010.508179

Hammond, K. (2014). The knowledge that 'flavours' a claim: towards building and assessing historical knowledge on three scales. Teaching History 157, 18-24. Retrieved from www.history.org.uk

Hattie, J., Marsh, H.W. Neill, J. T. \& Richards, G.E. (1997). Adventure education and outward bound: Out-of-class experiences that make a lasting difference. Review of Educational Research, 67, 43-87. doi: 10.3102/00346543067001043

Hirsch, E.D. (1987). Cultural literacy: What every American needs to know. New York: Vintage Books.

House of Commons (2010). Transforming education outside the classroom. Sixth Report. Children, schools and families committee. London: The Stationery Office Limited.

Howden, E. (2012). Outdoor experiential education: Learning through the body. New Directions for Adult and Continuing Education, 134, 43-51. doi: 10.1002/ace Howson, J. \& Shemilt, D. (2011). Frameworks of knowledge: dilemmas and debates. In I. Davies (Ed.), Debates in History Teaching (pp. 73-83). Abingdon: Routledge. Humberstone, B. \& Stan, I. (2011): Outdoor learning: primary pupils' experiences and teachers' interaction in outdoor learning. Education 3-13: International Journal of Primary, Elementary and Early Years Education, 39, 529-540. doi: $10.1080 / 03004279.2010 .487837$

Husbands, C. (1996). What is history teaching? Buckingham: Open University Press. Kendall, S. \& Rodger, J. (2015). Paul Hamlyn Foundation evaluation of learning away: Final report. Leeds: York Consulting LLP.

Kitson, A., Husbands, C. \& Steward, S. (2011) Teaching and learning history 11-18. Maidenhead: McGraw Hill/Open University Press.

Kolb, D. (1984). Experiential learning: Experience as the source of learning and development. Englewood Cliffs, N.J.: Prentice Hall.

Laevers, F. (1994). The innovative project: Experiential Education and the definition of quality in education. In F. Laevers (Ed.), Defining and assessing quality in early childhood education (pp. 159-172). Studia Paedagogica. Leuven, Leuven University Press. 
Lee, P. (2011). History education and historical literacy. In I. Davies (Ed.), Debates in history teaching (pp. 63-72). Abingdon: Routledge.

Levin, B. (2010). Governments and education reform: some lessons from the last 50 years. Journal of Education Policy, 25, 739-747. doi:

$10.1080 / 02680939.2010 .523793$

Maynard, T. \& Waters, J. (2007). Learning in the outdoor environment: a missed opportunity? Early Years, 27, 255-265. doi: 10.1080/09575140701594400

Nundy, S. (2001). Raising achievement through the environment: the case for fieldwork and field centres. Doncaster: National Association of Field Studies Officers.

Phillips, R. (2002). Reflective teaching of history 11-18. London: Continuum.

Quibell, T., Charlton, J. \& Law, J. (2017). Wilderness Schooling: a controlled trial of the impact of an outdoor education programme on attainment outcomes in primary school pupils. British Educational Research Journal, 43, 572-587. doi: 0.1002/berj.3273

Rickinson, M., Dillon, J., Teamey, K., Morris, M., Choi, M. Y., Sanders, D. \& Benefield, P. (2004). A review of research on outdoor learning. Shrewsbury: Field Studies Council.

Shemilt, D. (1987), Adolescent ideas about evidence and methodology in history. In C. Portal (Ed.), The history curriculum for teachers (pp.39-61). London: The Falmer Press.

State Education and Environment Roundtable (2005). The effects of environment-based education on student achievement: phase 2. Retrieved from http://www.seer.org/pages/research/CSAPII2005.pdf

Taniguchi, S., Freeman, P. \& LeGrand Richards, A. (2005). Attributes of meaningful learning experiences in an outdoor education program. Journal of Adventure Education and Outdoor Learning, 5, 131-144. doi. 10.1080/14729670585200661

Williams, A. \& Wainwright, N. (2016a). A new pedagogical model for adventure in the curriculum: part one - advocating for the model. Physical Education and Sport Pedagogy, 21, 481-500. doi: 10.1080/17408989.2015.1048211

Williams, A. \& Wainwright, N. (2016b). A new pedagogical model for adventure in the curriculum: part two - outlining the model. Physical Education and Sport Pedagogy, 21, 589-602. doi: 10.1080/17408989.2015.1048212 
Winter, C. (2012). School curriculum, globalisation and the constitution of policy problems and solutions. Journal of Education Policy, 27, 295-314. doi: 10.1080/02680939.2011.609911 